\title{
Simultaneous Inboard and Outboard, Inflight Measurements of Ultrafine Particle Concentrations
}

\section{Paul I. Williams ${ }^{1,2} \&$ Jamie Trembath ${ }^{3}$}

\author{
${ }^{1}$ Centre for Atmospheric Science, The University of Manchester, Manchester, UK \\ 2National Centre for Atmospheric Science, The University of Manchester, Manchester, UK \\ ${ }^{3}$ FAAM, Cranfield University, Bedford, MK43 OAL, UK
}

International Aircraft Cabin Air Conference 2021 Online, 15 - 18 March 2021 


\section{Overview}

- Motivation \& the UK research aircraft

- The 3686 LP Ultrafine Condensation Particle Counter

- Data - total of 12 flights, 3 with aerosol composition

- Conclusion 


\section{Motivation}

- Pre-pandemic, on average 4 billion passengers per annum.

- The indoor-outdoor interface at airports is unique - distinct from urban, for example.

- Exceptionally high concentrations of UFP from aircraft engines.

- Inflight events of UFPs have been reported. 


\section{Motivation}

- Inflight events - suggestions are ingress of external air, cooking, passengers and contamination of bleed air (oil or decomposition products such as TCP).

- Previous studies speculate source of aerosol only. 


\section{BAe 146 research aircraft}

A BAe 146 aircraft $4000 \mathrm{~kg}$ of science equipment and 18 people

Duration of 1-6 hours Range: surface to $10 \mathrm{~km}$ Reduce galley - Hot drinks only
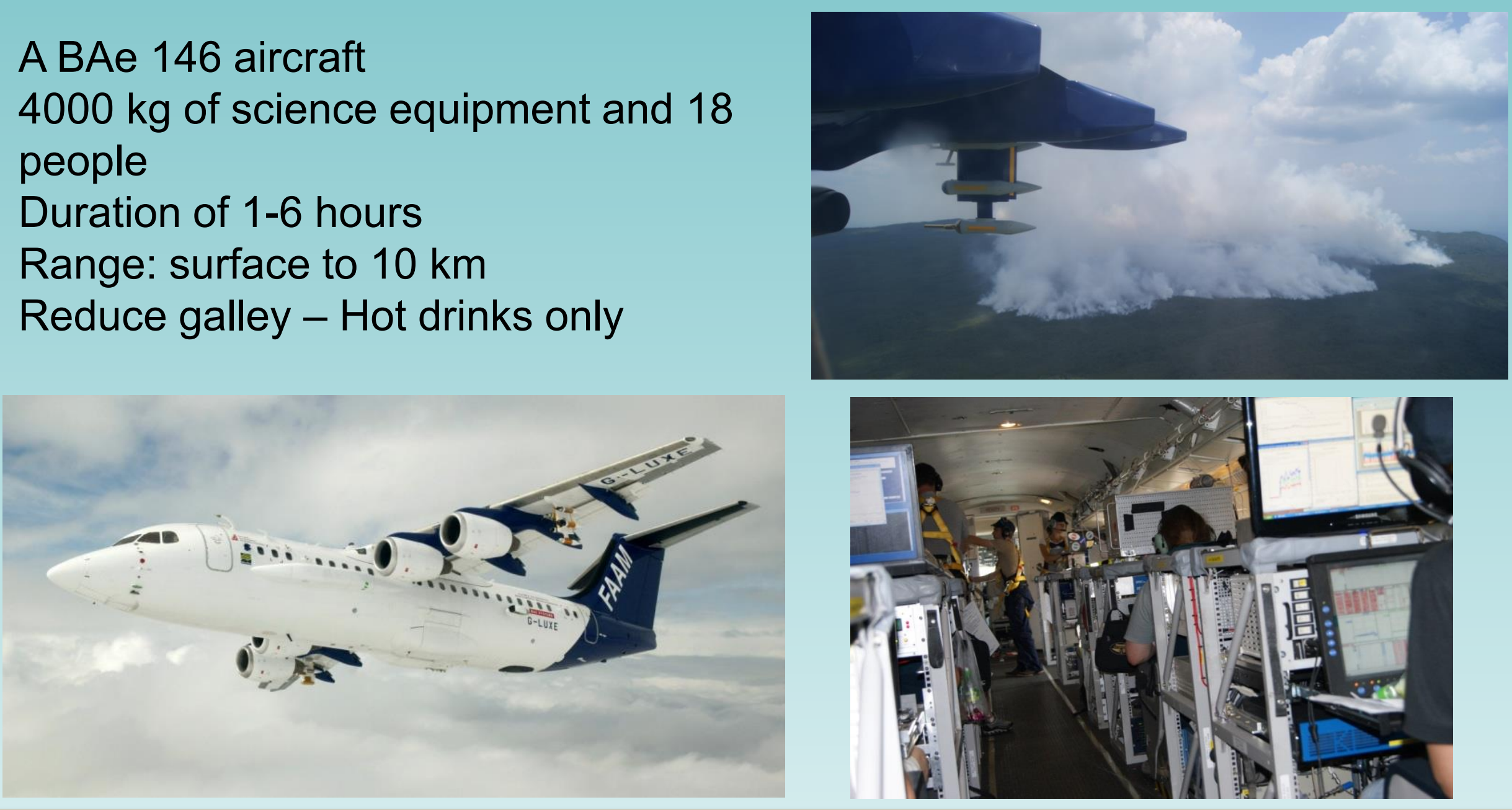

Visit www.faam.ac.uk 


\section{Quant/TSI 3786 LP UCPC}

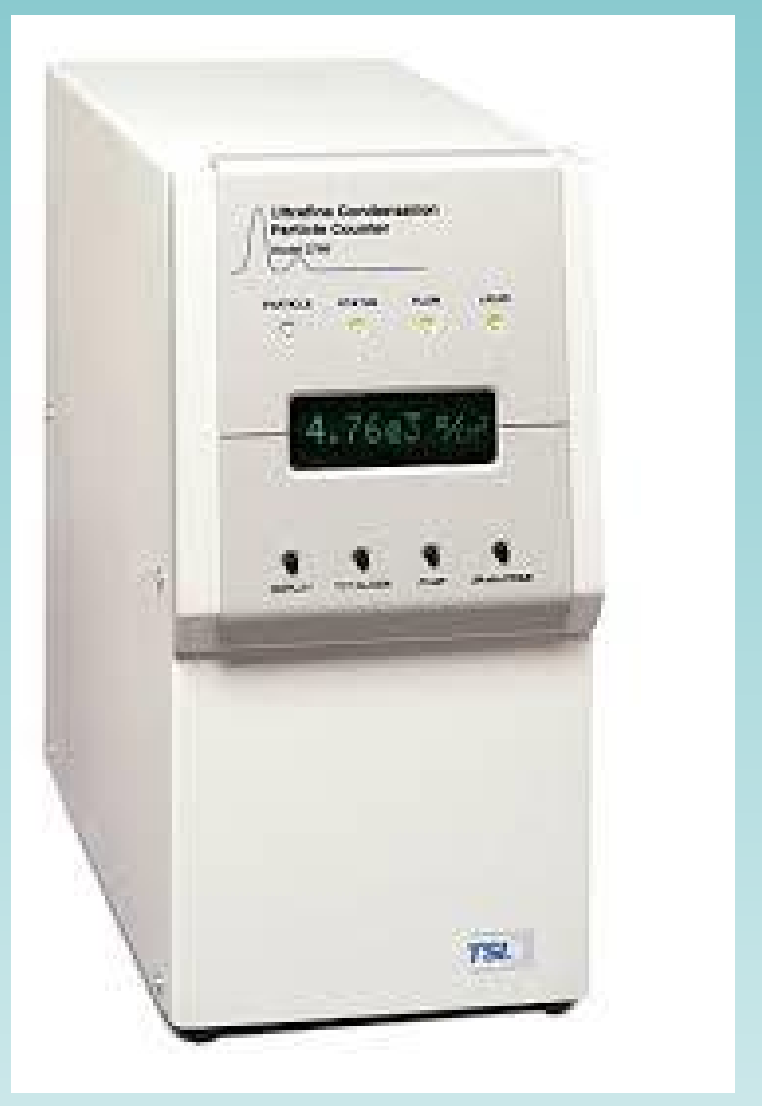

- Water based UCPC

- A modified version of a 3786 for low pressure applications

- $\mathrm{D}_{50} 2.5 \mathrm{~nm}$

- Range: Ambient to $180 \mathrm{hPa}$

- Single count mode to $9.99 \mathrm{e}^{5}$ $\mathrm{cm}^{-3}$

- Sadly obsolete 


\section{LP performance}

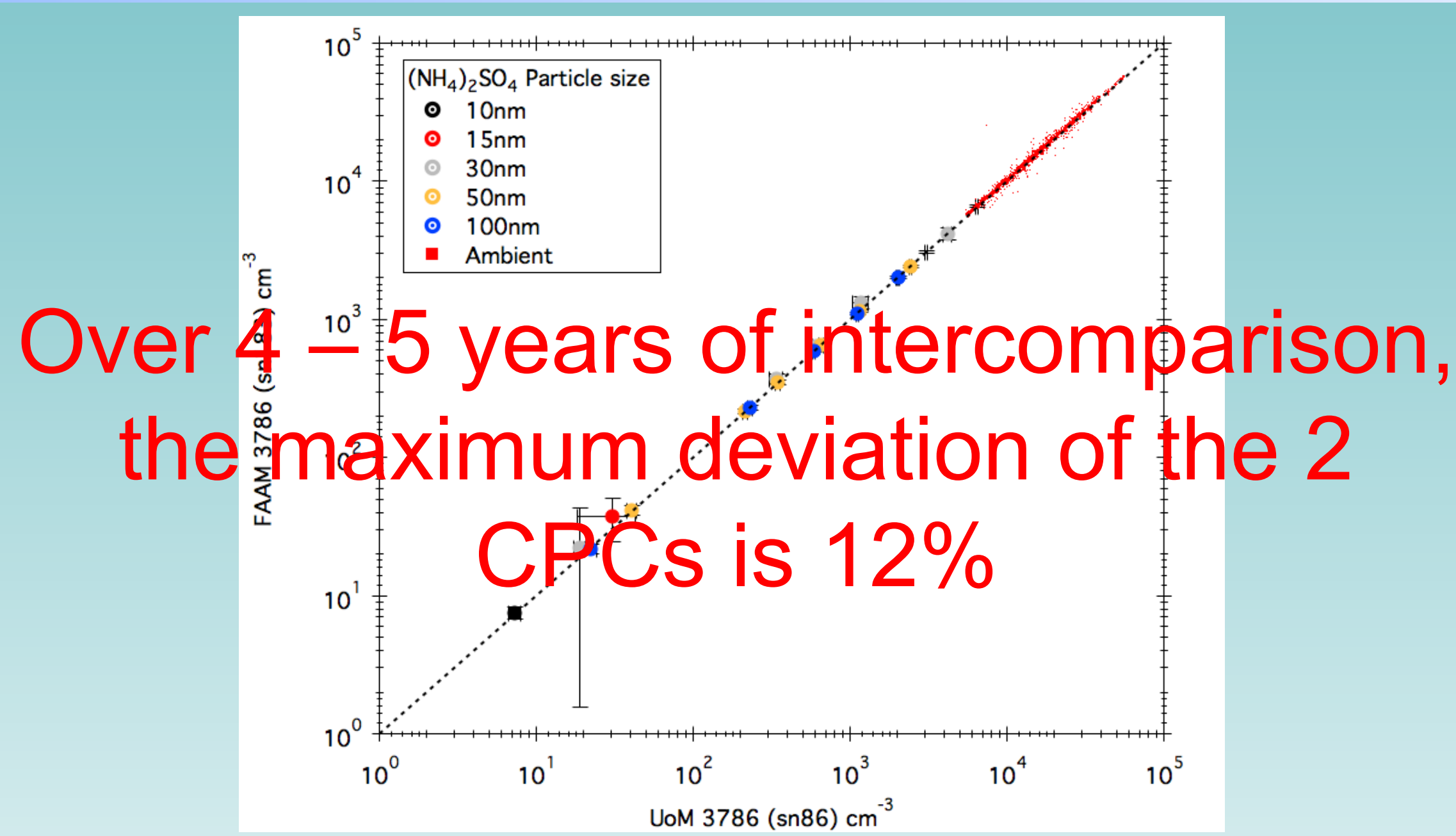




\section{Data -opportunist sampling}

- Volcanic and Atmospheric Near- to farfield Analysis of plumes Helping Interpretation and Modelling (VANAHEIM

- based at Keflavik, Iceland)

- Methane Observations and Yearly Assessments (MOYA - Dakar, Senegal)

- Cloud and Aerosols Radiative Impact and Forcing (CLARIFY - Ascension Island). 


\section{Results - P153 transit style}

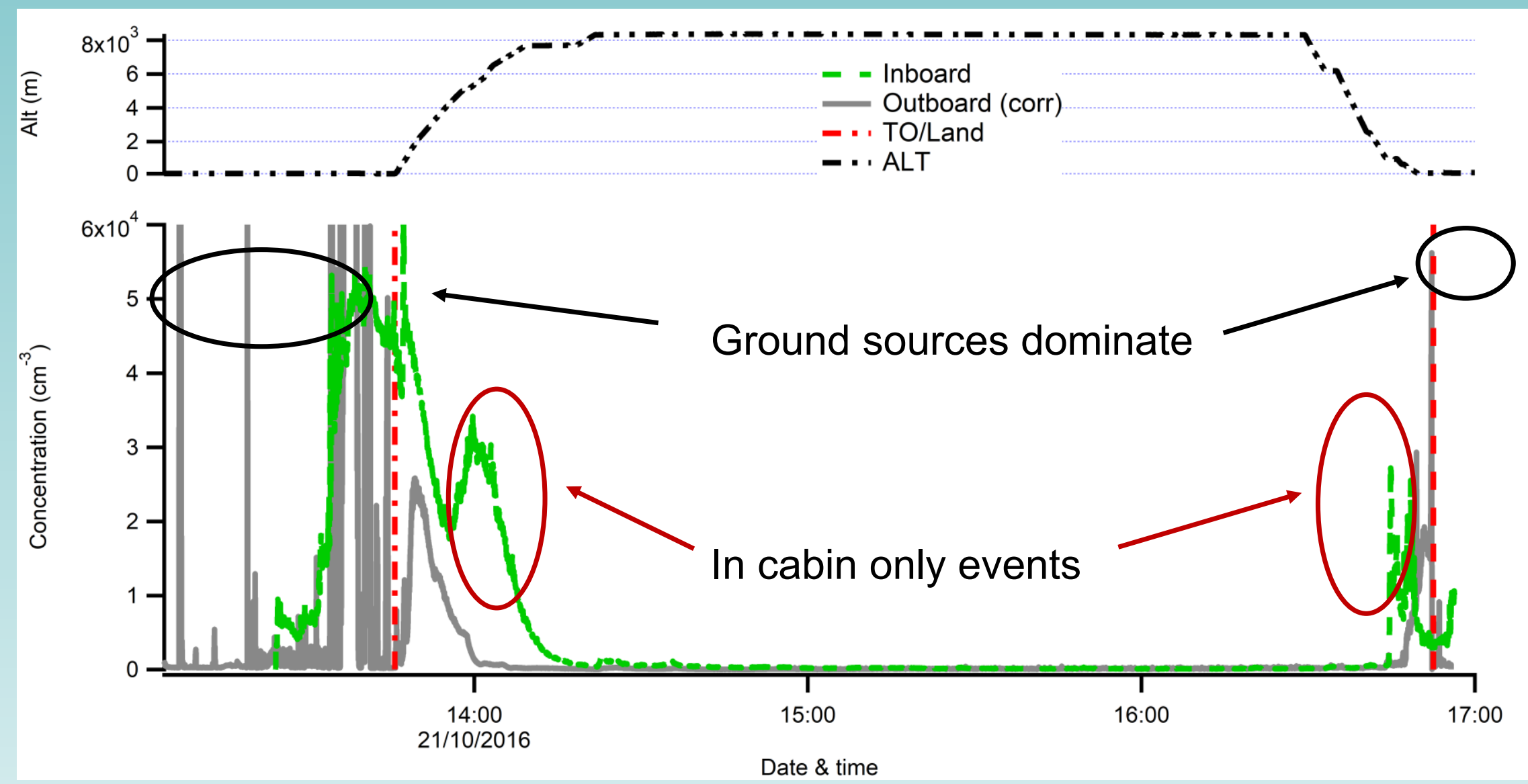




\section{Plume event and in cabin}

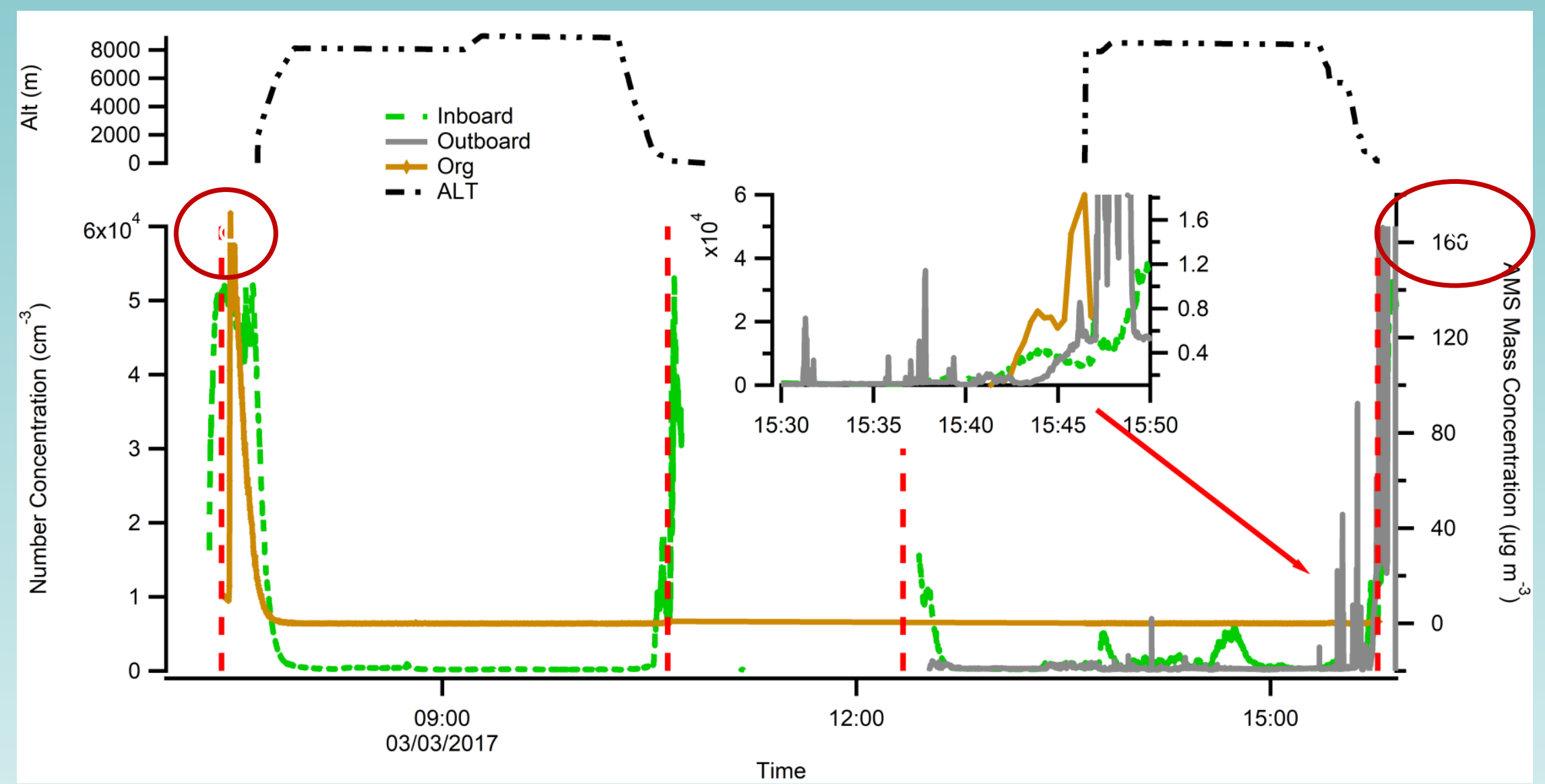




\section{C008 landing - oil contribution?}

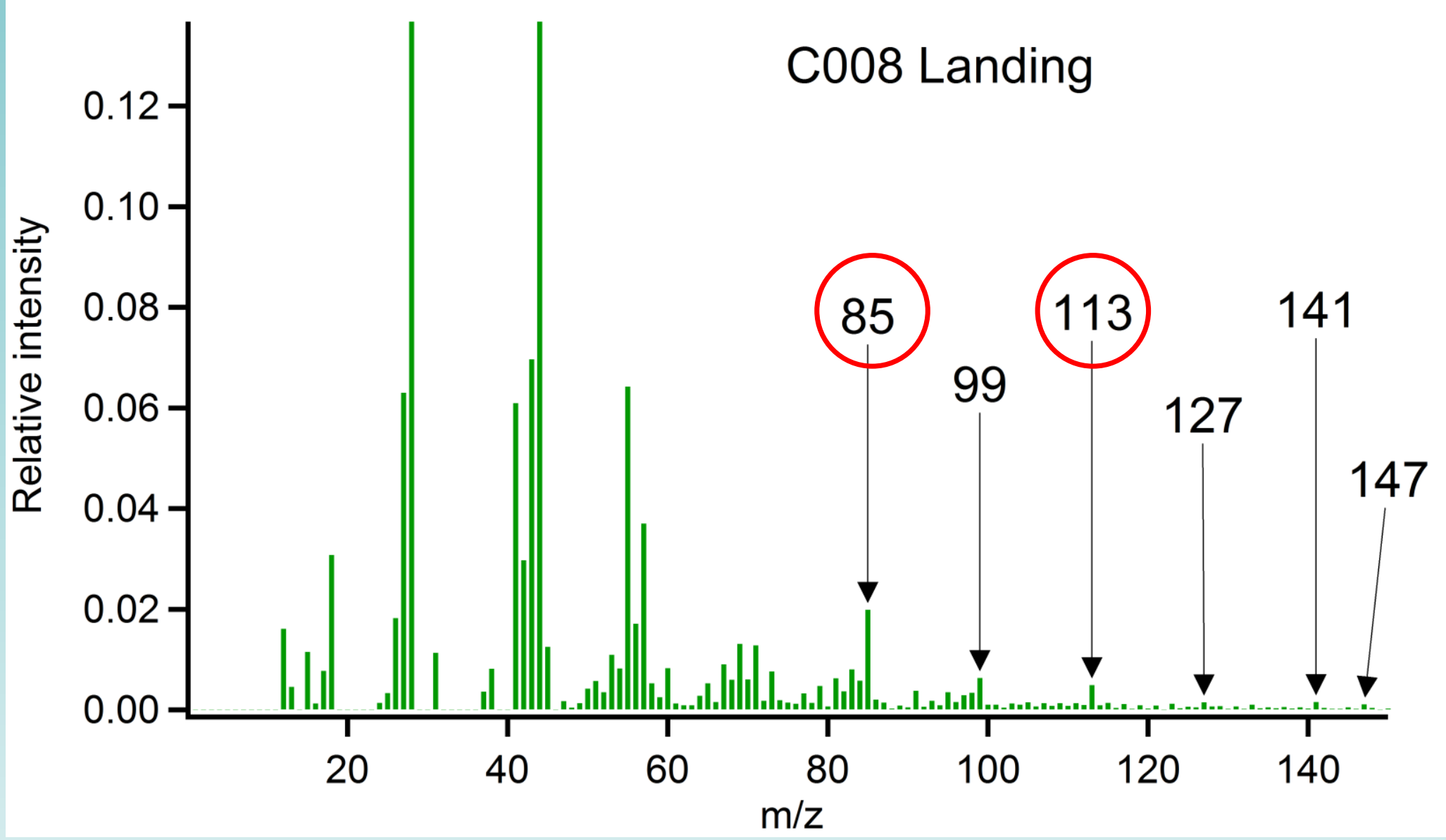




\section{C040 Results - oil?}

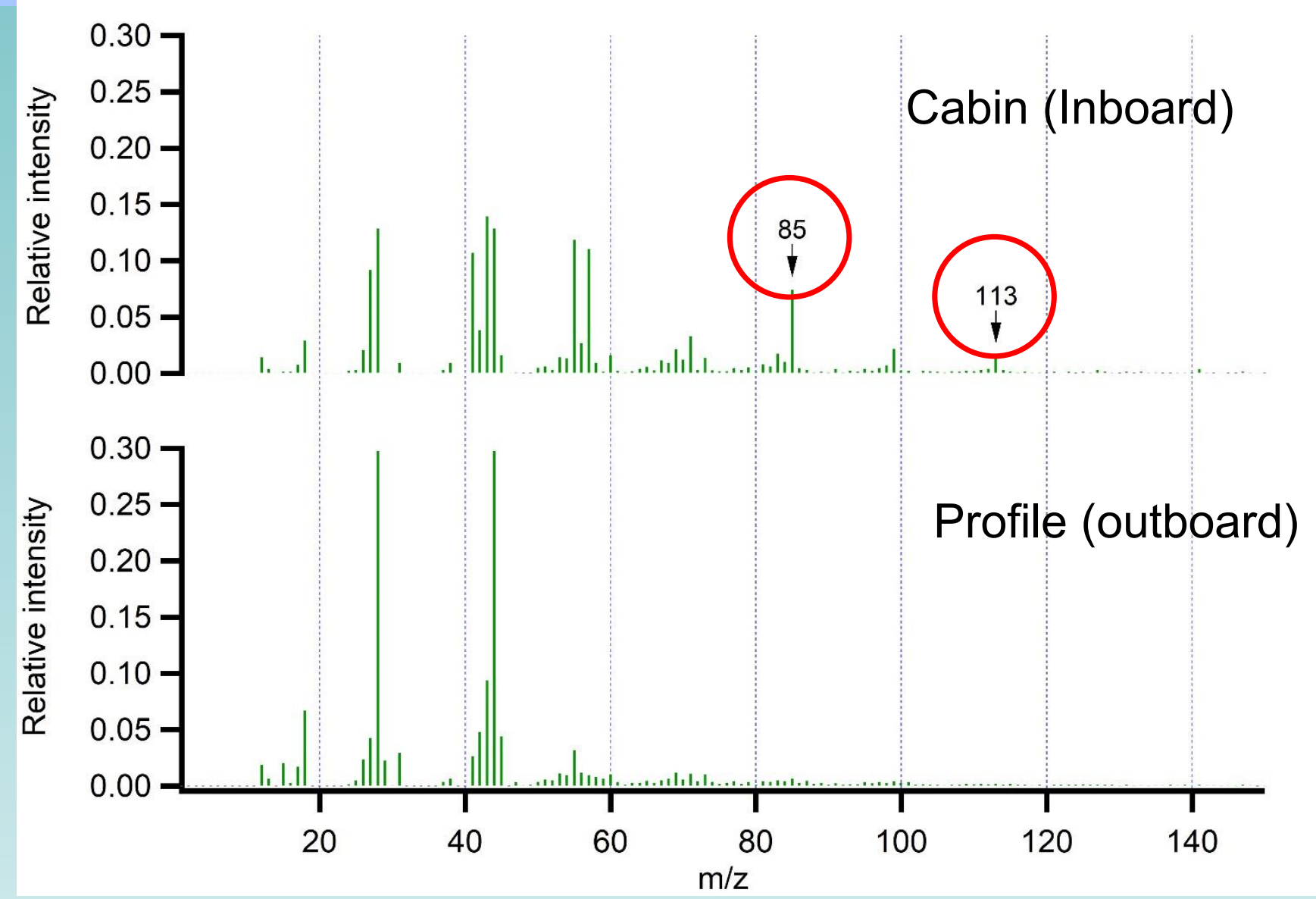




\section{Context - number}

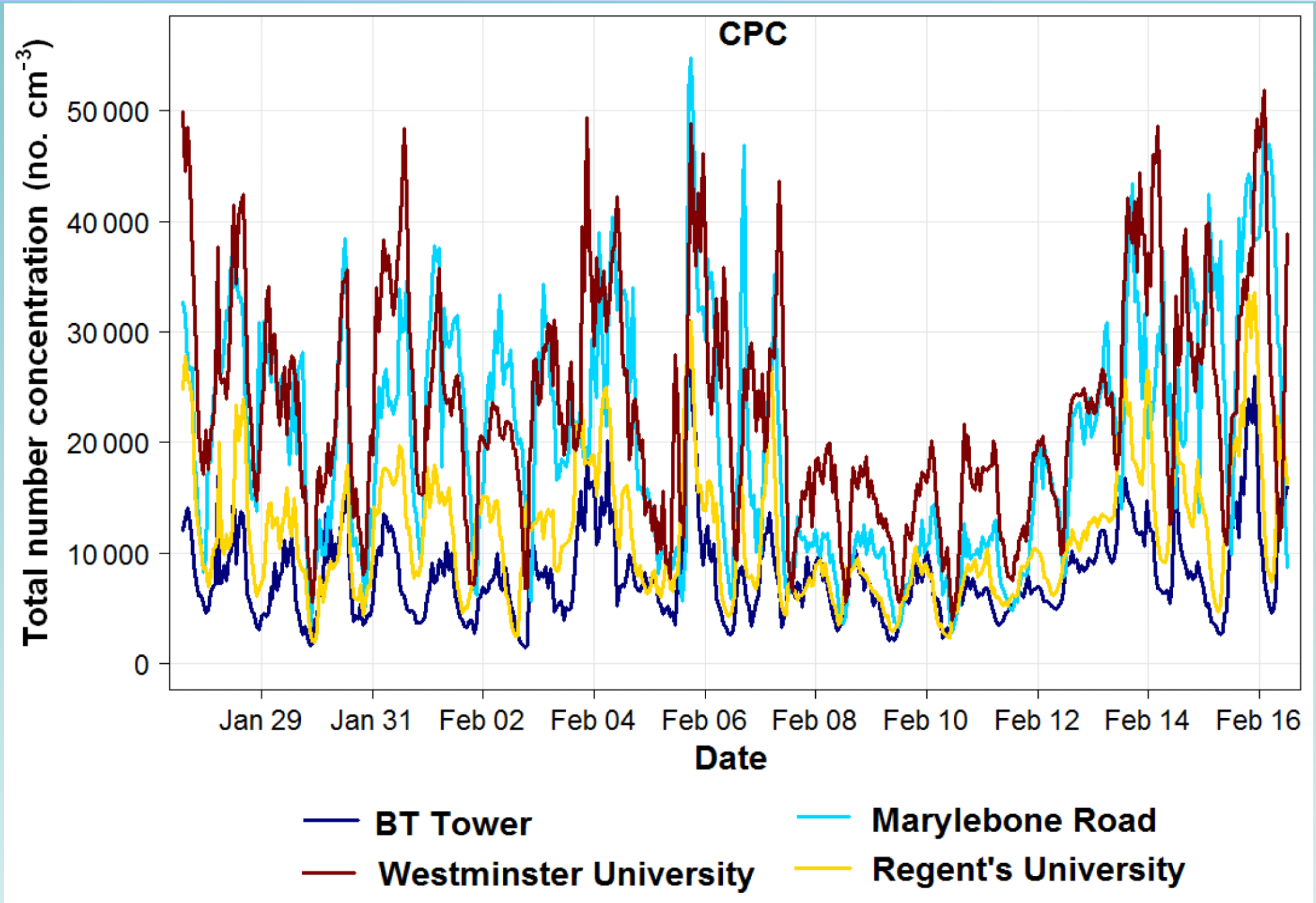

Harrison et al., ACP., 19, 39-55, 2019 https://doi.org/10.5194/acp-19-39-2019 CAQ, March 2021 


\section{Context - number}

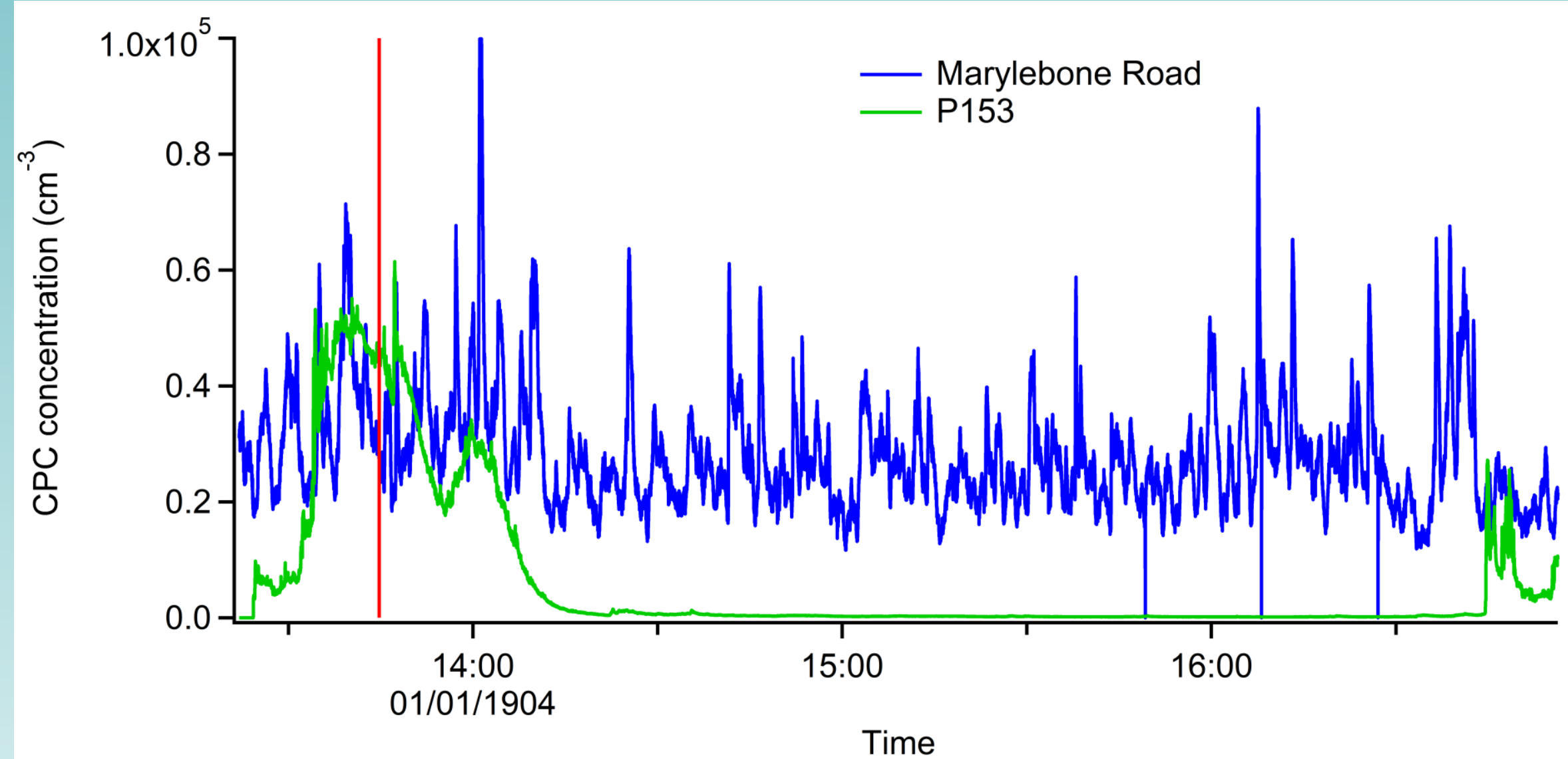




\section{Context - mass}
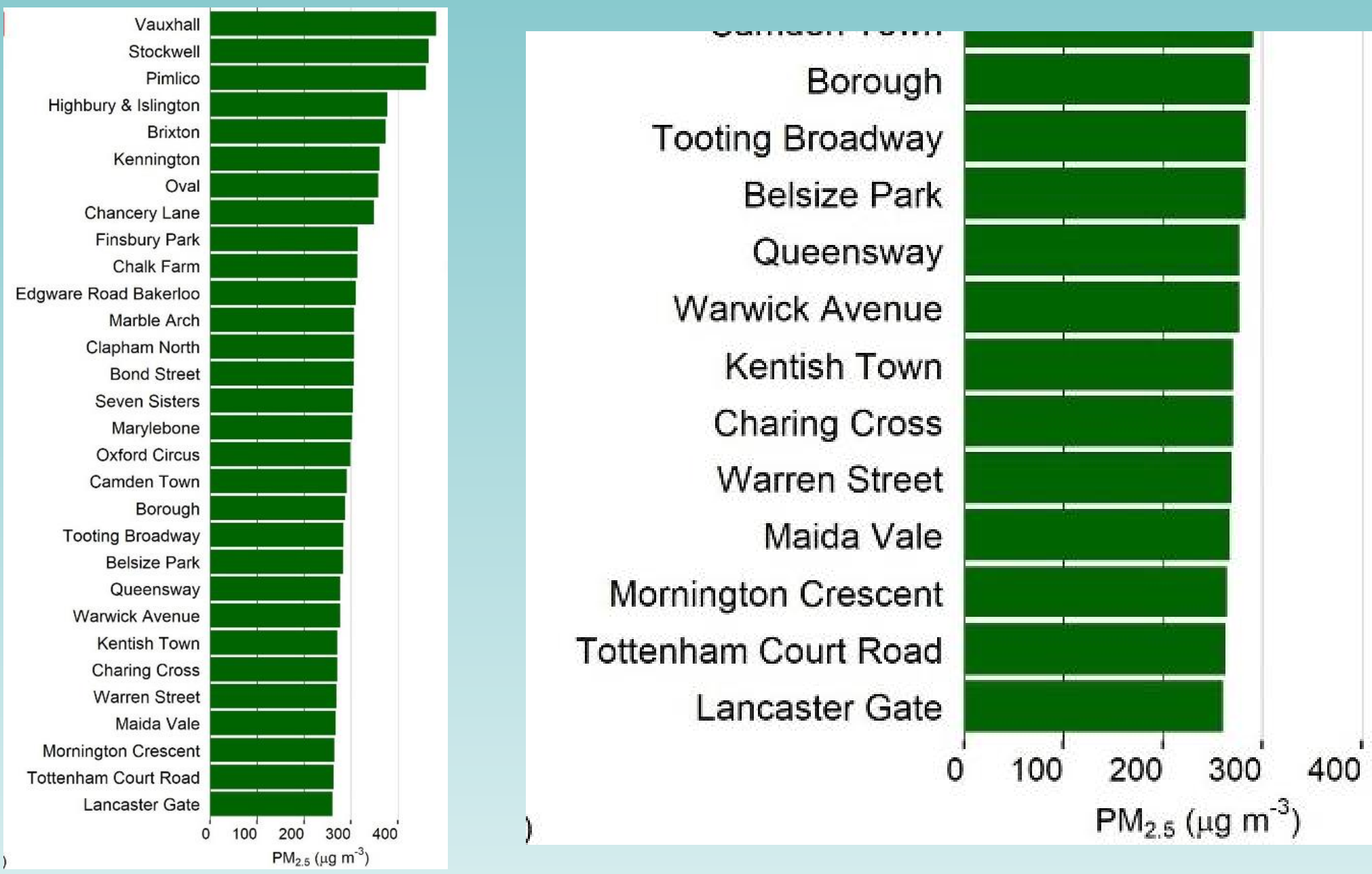

Smith et al., 2020, Env. Int., https://doi.org/10.1016/j.envint.2019.105188 CAQ, March 2021 


\section{Context - mass}
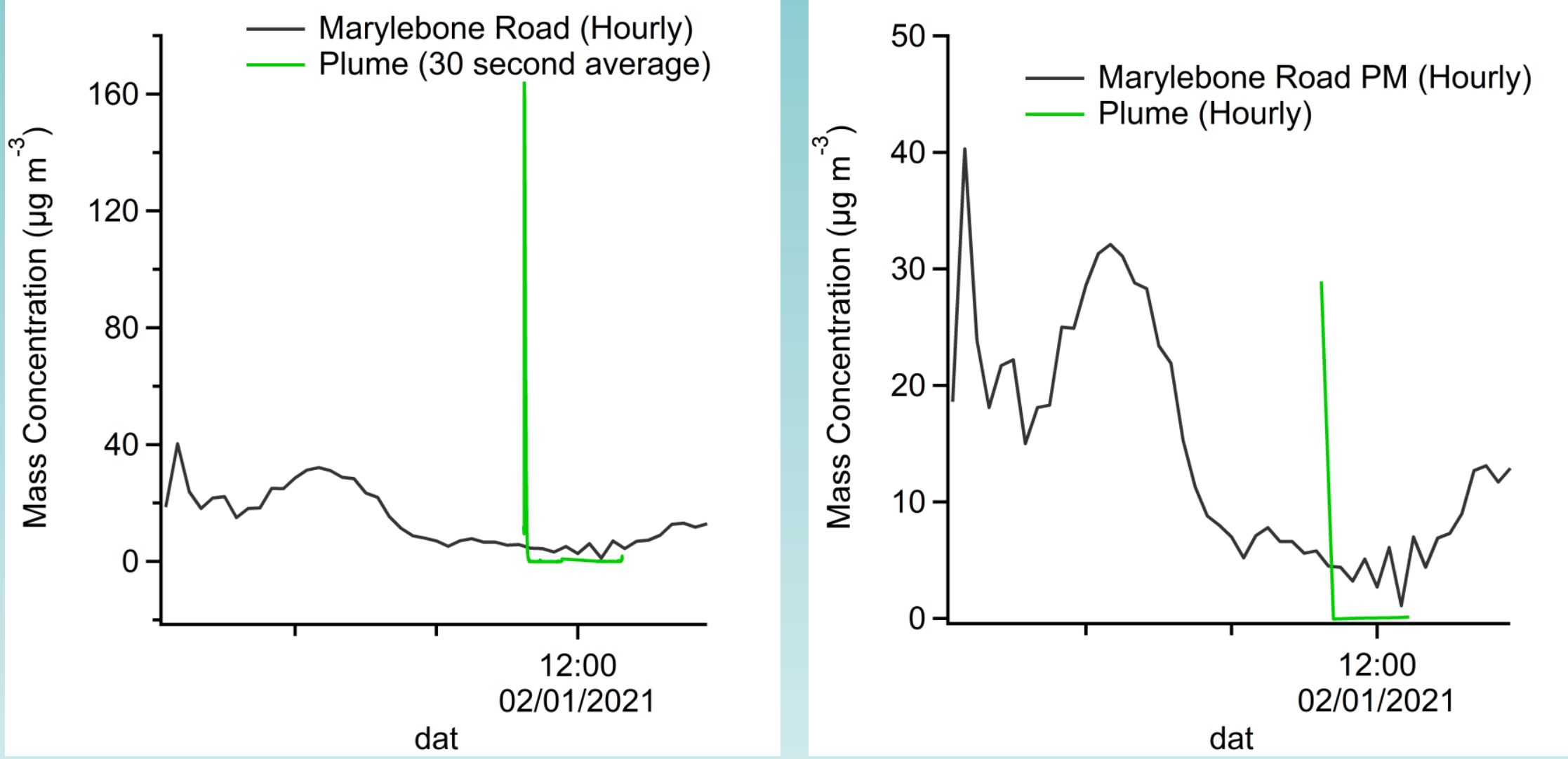

Marylebone Road, AURN data

CAQ, March 2021 


\section{Conclusions}

- On the ground, before doors close, the number is dominated by ground sources.

- Number inside the cabin peak after doors close in $75 \%$ of flights.

- In flight, in cabin only UFP events occur in over $50 \%$ of cases on approach - change in aircraft engine.

- Chemical composition is a mixture of sources, but oil appears to be one component for the 146 .

- There needs to be at least 3 parameters to have some confidence to identify the source of aerosol. 


\section{Conclusions}

- Converting to average concentration, total exposure (ug $\mathrm{m}^{-}$ ${ }^{3}$ hour) and average exposure per flight for mass all produce values below current workplace limits (comparing to 8 hour day) and ambient air quality limits.

- Calculated first estimate of number concentration total exposure and exposure per flight between 23,000 $60,000 \mathrm{~N} \mathrm{~cm}^{-3}$ Hour and 6,800 - 10,800 $\mathrm{N} \mathrm{cm}^{-3}$ per flight.

- Number concentration - equivalent to a London main road for events

- Mass concentration - Better than the underground; similar/worse* then main road ( ${ }^{*}$ delete as appropriate)

- published AS\&T, 2021, https://doi.org/10.1080/02786826.2021.1880544 